\title{
BIOLOGIA DA FERIDA E CICATRIZAÇÃO
}

\author{
WOUND BIOLOGY AND HEALING
}

Maria de Fátima G S Tazima ${ }^{1}$, Yvone Avalloni de Morais Villela de Andrade Vicente ${ }^{1}$, Takachi Moriya ${ }^{2}$

${ }^{1}$ Docente da Divisão de Cirurgia Pediátrica, ${ }^{2}$ Docente da Divisão de Cirurgia Vascular e Endovascular. Departamento de Cirurgia e Anatomia da FMRP-USP.

Correspondência: Maria de Fátima G S Tazima. Divisão de Cirurgia Pediátrica, Departamento de Cirurgia e Anatomia da FMRP-USP. Av. Bandeirantes, 3900. CEP: 14048-900 - Ribeirão Preto/SP. (email: mftazima@ terra.com.br)

Tazima MFGS, Vicente YAMVA, Moriya T. Biologia da ferida e cicatrização. Medicina (Ribeirão Preto) 2008; 41 (3): 259-64.

RESUMO: O conhecimento dos complexos eventos fisiológicos da cicatrização da ferida é de grande importância para o cirurgião. A reparação das feridas é apresentada em suas etapas inflamatória, proliferativa e de maturação.

Palavras-chaves: Cicatrização de Feridas. Ferimentos e Lesões/cirurgia. Ferida Operatória. Biologia da Ferida. Biologia/Ferimentos e Lesões.

O reparo de feridas, uma solução de continuidade dos tecidos, decorrente da lesão por agentes mecânicos, térmicos, químicos e bacterianos, é o esforço dos tecidos para restaurar a função e estruturas normais.

O conhecimento dos complexos eventos fisiológicos da cicatrização de feridas é de grande importância para o cirurgião.

A regeneração é a restauração perfeita da arquitetura do tecido pré-existente, na ausência de formação de cicatriz, e embora seja o tipo ideal no universo de cicatrização de feridas, ela só é observada no desenvolvimento embrionário, organismos inferiores ou em determinados tecidos como ossos e fígado. $\mathrm{Na}$ cicatrização de feridas a acurácia da regeneração é trocada pela velocidade de reparo.

A reparação de feridas passa pelas seguintes etapas básicas: fase inflamatória, fase proliferativa (que incluem reepitelização, síntese da matriz e neovascularização) e fase de maturação.

\section{1- FASE INFLAMATÓRIA}

Inicia-se no exato momento da lesão. O sangramento traz consigo plaquetas, hemácias e fibrina, selando as bordas da ferida, ainda sem valor mecânico, mas facilitando as trocas. O coágulo formado estabelece uma barreira impermeabilizante que protege da contaminação. Com a lesão tecidual, há liberação local de histamina, serotonina e bradicinina que causam vasodilatação e aumento de fluxo sanguíneo no local e, conseqüentemente, sinais inflamatórios como calor e rubor. A permeabilidade capilar aumenta causando extravasamento de líquidos para o espaço extracelular, e conseqüente edema.

A resposta inflamatória, que perdura cerca de três dias,e na qual ocorre a migração seqüencial das células para a ferida é facilitada por mediadores bioquímicos que aumentam a permeabilidade vascular, favorecendo a exsudação plasmática e a passagem de elementos celulares para a área da ferida. Os mediadores bioquímicos de ação curta são a histamina e serotonina e as mais duradouras são a leucotaxina, bradicinina e prostaglandina. A prostaglandina é um dos mediadores mais importantes no processo de cicatrização, pois além de favorecer a exsudação vascular, estimula a mitose celular e a quimiotaxia de leucócitos.

Os primeiros elementos celulares a alcançar o local da ferida são os neutrófilos e os monócitos, com 
a função de desbridar as superfícies da ferida e fagocitar as partículas antigênicas e corpos estranhos. O pico de atividade dos polimorfonucleares ocorre nas primeiras 24-48 horas após o trauma, seguindo-se de um maior aporte de macrófagos durante os dois a três dias seguintes. O macrófago, também ativa os elementos celulares das fases subseqüentes da cicatrização tais como fibroblastos e células endoteliais (Figura 1).

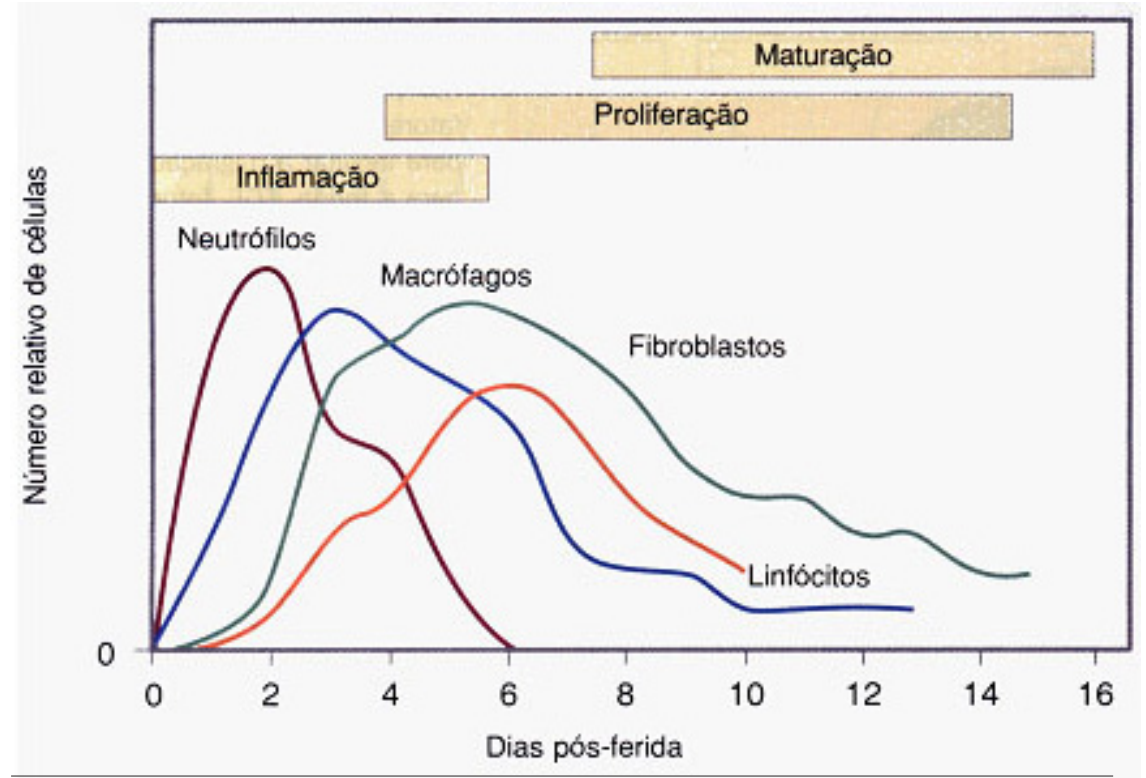

Figura 1: Evolução do número relativo de células sangüineas e fibroblastos nas fases seqüenciais do processo de cicatrização.

\section{2- FASE PROLIFERATIVA}

A fase proliferativa é composta de três eventos importantes que sucedem o período de maior atividade da fase inflamatória: neo-angiogênese, fibroplasia e epitelização. Este fase caracteriza-se pela formação de tecido de granulação, que é constituído por um leito capilar, fibroblastos, macrófagos, um frouxo arranjo de colágeno, fibronectina e ácido hialurônico. Esta fase inicia-se por volta do $3^{\circ}$ dia após a lesão, perdura por 2 a 3 semanas e é o marco inicial da formação da cicatriz.

\section{1- Neo-angiogênese}

A neo-angiogênese é o processo de formação de novos vasos sangüíneos, necessário para manter o ambiente de cicatrização da ferida. Em todas as feridas, o suprimento sanguíneo dos fibroblastos responsáveis pela síntese de colágeno provém de um intenso crescimento de novos vasos, caracterizando a cicatrização por segunda intenção e o tecido de granulação.

Os novos vasos formam-se a partir de brotos endoteliais sólidos, que migram no sentido da periferia para o centro da ferida, sobre a malha de fibrina depositada no leito da ferida. A bradicinina, a prostaglandina e outros mediadores químicos oriundos dos macrófagos, ativados, estimulam a migração e a mitose das células endoteliais. A neo-angiogênese é responsável não apenas pela nutrição do tecido, com uma demanda metabólica maior, como também pelo aumento do aporte de células, como macrófagos e fibroblastos, para o local da ferida.

\section{2- Fibroplasia}

Após o trauma, células mesenquimais normalmente quiescentes e esparsas no tecido normal, são transformadas em fibroblastos e atraídas para o local inflamatório, onde se dividem e produzem os componentes da matriz extracelular. O fibroblasto só aparece no sítio da lesão a partir do $3^{\circ}$ dia, quando os leucócitos polimorfonucleares já fizeram seu papel higienizador da área traumatizada. A função primordial dos fibroblastos é sintetizar colágeno, ainda na fase celular da inflamação.

O colágeno é uma proteína de alto peso molecular, composta de glicina, prolina, hidroxiprolina, lisina e hidroxilisina, que se organiza em cadeias longas de três feixes polipeptídicos em forma de hélice, responsáveis pela força da cicatriz.

A síntese de colágeno é dependente da oxigenação das células, da hidroxilação da prolina e lisina, reação essa mediada por uma enzima produzida pelo próprio fibroblasto, em presença de co-enzimas (vitaminas A, C e E), ferro, testosterona, tiroxina, proteínas e zinco.

O colágeno é o material responsável pela sustentação e pela força tensil da cicatriz, produzido e degradado continuamente pelos fibroblastos. Inicialmente, a síntese de colágeno novo é a principal responsável pela força da cicatriz, sendo substituída ao longo de semanas, pela formação de ligações cruzadas entre os feixes de colágeno. A taxa de síntese 
declina por volta de quatro semanas e se equilibra com a taxa de destruição e, então, se inicia a fase de maturação do colágeno que continua por meses, ou mesmo anos.

\section{3- Epitelização}

Nas primeiras 24 a 36 horas após a lesão, fatores de crescimento epidérmicos estimulam a proliferação de células do epitélio. Na pele os ceratinócitos são capazes de sintetizar diversas citocinas que estimulam a cicatrização das feridas cutâneas.

As células epiteliais migram, a partir das bordas, sobre a área cruenta, da ferida e dos folículos pilosos próximos, induzindo a contração e a neoepitelização da ferida e, assim, reduzindo a sua superfície. Os ceratinócitos, localizados na camada basal da epiderme residual ou na profundidade de apêndices dérmicos, revestidos de epitélio, migram para recobrir a ferida. As células epiteliais movem-se, aos saltos e desordenadamente, até as bordas, aproximando-as. A epitelização envolve uma sequiência de alterações nos ceratinócitos da ferida: separação, migração, proliferação, diferenciação e estratificação.

\section{4- Matriz Extracelular}

A matriz extracelular, também conhecida como substância fundamental, substitui rapidamente o coágulo depositado no leito da ferida logo após o trauma. A principal função da matriz é a restauração da continuidade do tecido lesado, funcionando como um arcabouço para a migração celular. Os fibroblastos são as maiores fontes de proteínas da matriz, onde irão ordenar os feixes de colágeno produzidos, também, pelos próprios fibroblastos, além de ser arcabouço para os vasos neoformados. É constituída de várias proteínas, como fibrina e colágeno, proteoglicanos (ácido hialurônico e condroítina), glicoproteínas (fibronectina e laminina), água e eletrólitos.

\section{3- FASE DE MATURAÇÃO}

\section{1- Contração da ferida}

A ferida sofre um processo de contração, por meio de um movimento centrípeto de toda a espessura da pele circundante, reduzindo a quantidade e o tamanho da cicatriz desordenada. Este processo é um importante aliado da cicatrização das feridas, princi- palmente nas abertas. Porém, se ocorre de forma exagerada e desordenada causa defeitos cicatriciais importantes por causa da diferenciação dos fibroblastos em miofibroblastos, estimulados por fatores de crescimento.

\section{2- Remodelação}

A maturação da ferida tem início durante a $3^{\mathrm{a}}$ semana e caracteriza-se por um aumento da resistência, sem aumento na quantidade de colágeno. Há um equilíbrio de produção e destruição das fibras de colágeno neste período, por ação da colagenase. $\mathrm{O}$ desequilíbrio desta relação favorece o aparecimento de cicatrizes hipertróficas e quelóides. O aumento da resistência deve-se à remodelagem das fibras de colágeno, com aumento das ligações transversas e melhor alinhamento do colágeno, ao longo das linhas de tensão. A fase de maturação dura toda a vida da ferida, embora o aumento da força tênsil se estabilize, após um ano, em 70 a $80 \%$ da pele intacta. A inclinação da curva de maturação é mais aguda durante as primeiras seis a oito semanas.

\section{3- Tipos de cicatrização de feridas}

Existem três formas pelas quais uma ferida pode cicatrizar, que dependem da quantidade de tecido lesado ou danificado e da presença ou não de infecção: primeira intenção, segunda intenção e terceira intenção (fechamento primário retardado).

- Primeira intenção: é o tipo de cicatrização que ocorre quando as bordas são apostas ou aproximadas, havendo perda mínima de tecido, ausência de infecção e mínimo edema. A formação de tecido de granulação não é visível. Exemplo: ferimento suturado cirurgicamente (Figura 2).

- Segunda intenção: neste tipo de cicatrização ocorre perda excessiva de tecido com a presença ou não de infecção. A aproximação primária das bordas não é possível. As feridas são deixadas abertas e se fecharão por meio de contração e epitelização.

- Terceira intenção: designa a aproximação das margens da ferida (pele e subcutâneo) após o tratamento aberto inicial. Isto ocorre principalmente quando há presença de infecção na ferida, que deve ser tratada primeiramente, para então ser suturada posteriormente. 
Cicatrizaçāo primária
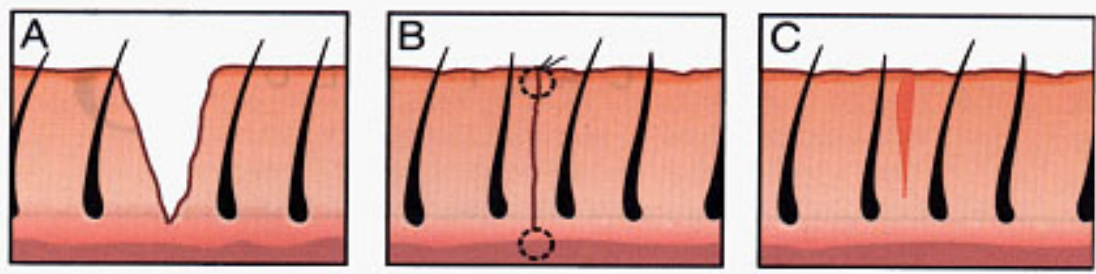

Cicatrizaçāo secundária
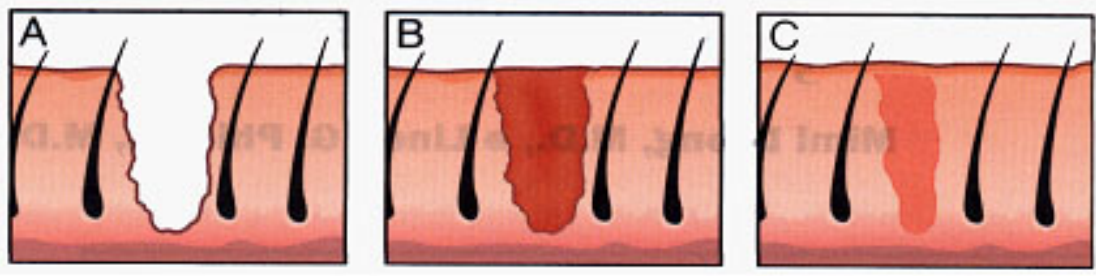

Figura 2: Representação esquemática da cicatrização por primiera e por segunda intenção.

- Limpa-contaminadas: são os ferimentos que apresentam contaminação grosseira, em acidente doméstico por exemplo ou em situações cirúrgicas em que houve contato com os tratos respiratório, digestivo, urinário e genital, porém em situações controladas. O risco de infecção é cerca de $10 \%$.

- Contaminadas: são consideradas contaminadas as feridas acidentais, com mais de seis horas de trauma ou que tiveram contato com terra e fezes, por exemplo. No ambiente cirúrgico são consideradas contaminadas as em que

\section{4- Classificação das feridas}

As feridas podem ser classificadas de três formas diferentes de acordo com o agente causal, o grau de contaminação e o comprometimento tecidual.

\subsection{1- Agente causal}

- Incisas ou cirúrgicas: são produzidas por um instrumento cortante. As feridas limpas são geralmente fechadas por suturas. Agentes: faca, bisturi, lâmina, etc.

- Contusas: são produzidas por objeto rombo e caracterizadas por traumatismo das partes moles, hemorragia e edema.

- Lacerantes: São ferimentos com margens irregulares e com mais de um ângulo. O mecanismo da lesão é por tração: rasgo ou arrancamento tecidual. Um exemplo clássico é a mordedura de cão.

- Perfurantes: são caracterizadas por pequenas aberturas na pele. Há um predomínio da profundidade sobre o comprimento. Exemplos: bala ou ponta de faca.

\subsection{2- Grau de contaminação}

As feridas podem ser limpas, limpa-contaminadas, contaminadas e infectadas.

- Limpas: são as que não apresentam sinais de infecção e em que não são atingidos os tratos respiratório, digestivo, genital ou urinário. Probabilidade de infecção é baixa, em torno de 1 a $5 \%$. Exemplo: feridas produzidas em ambiente cirúrgico. a técnica asséptica não foi devidamente respeitada. Os níveis de infecção podem atingir 20 a 30\% (cirurgia dos cólons).

- Infectadas: são aquelas que apresentam sinais nítidos de infecção.

\subsection{3- Comprometimento tecidual}

- Estágio I: comprometimento da epiderme apenas, sem perda tecidual.

- Estágio II: ocorre perda tecidual e comprometimento da epiderme, derme ou ambas.

- Estágio III: há comprometimento total da pele e necrose de tecido subcutâneo, entretanto não atinge a fáscia muscular.

- Estágio IV: há extensa destruição de tecido, chegando a ocorrer lesão óssea ou muscular ou necrose tissular.

\section{5- Fatores que interferem na cicatrização}

Vários fatores locais e gerais podem interferir em maior ou menor grau no processo de cicatrização, entretanto em muitos deles o cirurgião pode interferir para otimizar o resultado final.

\subsection{1- Fatores locais}

Os fatores locais são relacionados às condições da ferida e como ela é tratada cirurgicamente (técnica cirúrgica).

- Vascularização das bordas da ferida: A boa irrigação das bordas da ferida é essencial para a cicatrização, pois permite aporte adequado de nutientes 
e oxigênio. Entretanto, a boa vascularização depende das condições gerais e co-morbidades do paciente, bem como do tratamento dado a esta ferida.

- Grau de contaminação da ferida: uma incisão cirúrgica realizada com boa técnica e em condições de assepsia tem melhor condição de cicatrização do que um ferimento traumático ocorrido fora do ambiente hospitalar. O cuidado mais elementar e eficiente é a limpeza mecânica, remoção de corpos estranhos, detritos e tecidos desvitalizados.

- Tratamento das feridas: assepsia e antissepsia, técnica cirúrgica correta (diérese, hemostasia e síntese), escolha de fio cirúrgico (que cause mínima reação tecidual), cuidados pós-operatórios adequados (curativos e retirada dos pontos), são alguns dos aspectos importantes a serem observados em relação ao tratamento das feridas.

\subsection{2- Fatores gerais}

Os fatores gerais estão relacionados às condições clínicas do paciente, e estas podem alterar a capacidade do paciente de cicatrizar com eficiência.

- Infecção: é provavelmente a causa mais comum de atraso na cicatrização. Se a contagem bacteriana na ferida exceder $10^{5}$ microorganismos/g de tecido ou se qualquer estreptococo B-hemolítico estiver presente, a ferida não cicatriza por qualquer meio, como suturas primárias, enxertos ou retalhos.

- Idade: quanto mais idoso o paciente menos flexíveis são os tecidos. Há uma diminuição progressiva de colágeno.

- Hiperatividade do paciente: a hiperatividade dificulta a aproximação das bordas da ferida. O repouso favorece a cicatrizção.

- Oxigenação e perfusão dos tecidos: doenças que alteram o fluxo sangüíneo normal podem afetar a distribuição dos nutrientes das células, assim como a dos componentes do sistema imune do corpo. Essas condições afetam a capacidade do organismo de transportar células de defesa e antibióticos, o que dificulta o processo de cicatrização. $O$ fumo reduz a hemoglobina funcional e leva à disfunção pulmonar, o que reduz o aporte de oxigênio para as células e dificulta a cura da ferida.

- Nutrição: uma deficiência nutricional pode dificultar a cicatrização, pois deprime o sistema imune e diminui a qualidade e a síntese de tecido de reparação. As carências de proteínas e de vitamina C são as mais importantes, pois afetam diretamente a sín- tese de colágeno. A vitamina A contrabalança os efeitos dos corticóides que inibem a contração da ferida e a proliferação de fibroblastos. A vitamina $\mathrm{B}$ aumenta o número de fibroblastos. A vitamina $\mathrm{D}$ facilita a absorção de cálcio e a E é um co-fator na síntese do colágeno, melhora a resistência da cicatriz e destrói radicais livres. O zinco é um co-fator de mais de 200 metaloenzimas envolvidas no crescimento celular e na síntese protéica, sendo, portanto, indispensável para a reparação dos tecidos.

- Diabetes: a diabetes melito prejudica a cicatrização de ferida em todos os estágios do processo. $\mathrm{O}$ paciente diabético com neuropatia associada e aterosclerose é propenso à isquemia tecidual, ao traumatismo repetitivo e à infecção.

- Medicamentos: Os corticosteróides, os quimioterápicos e os radioterápicos podem reduzir a cicatrização de feridas, pois interferem na resposta imunológica normal à lesão. Eles interferem na síntese protéica ou divisão celular agindo diretamente na produção de colágeno. Além do mais, aumentam a atividade da colagenase, tornando a cicatriz mais frágil.

- Estado imunológico: nas doenças imunossupressoras, a fase inflamatória está comprometida pela redução de leucócitos, com conseqüente retardo da fagocitose e da lise de restos celulares. Pela ausência de monócitos a formação de fibroblastos é deficitária.

Além destes fatores acima mencionados, longos períodos de internação hospitalar e tempo cirúrgico elevado são também aspectos complicadores importantes para o processo de cicatrização.

\section{4- RETIRADA DOS PONTOS}

De modo geral a retirada dos pontos deve ser feita entre o $6^{\circ}$ e $7^{\circ}$ dias de pós-operatório, para suturas simples com pontos separados. Nas incisões que seguem as linhas de força da pele e os pontos foram dados sem tensão, os pontos podem ser retirados mais precocemente, em torno do $4^{\circ}$ dia de pós-operatório. Em suturas intradérmicas contínuas com fios não absorvíveis, os pontos devem permanecer por até 12 dias.

Em condições adversas (infecção, desnutrição, neoplasias, diabetes, déficits de vitaminas e oligoelementos, etc) os pontos devem ser removidos mais tardiamente, isto é, entre o $10^{\circ}$ e $12^{\circ}$ dias de pósoperatório. 
Tazima MFGS, Vicente YAMVA, Moriya T. Wound biology and healing. Medicina (Ribeirão Preto) 2008; 41 (3): 259-64.

ABSTRACT: A profound knowledge about the complex physiological processes underlying the cicatrization of wounds is crucial for any surgeon. Here, the following stages of wound regeneration are emphasized: inflammation, proliferation, and maturation.

keywords: Wound Healing. Wounds And Injuries/Surgery. Surgical Wound. Biology, Wound. Biology/Wounds and Injuries.

\section{BIBLIOGRAFIA RECOMENDADA}

1 - Fischer JE. Mastery of surgery. Willianas \& Willians. Philadelphia, 5 st. Ed., 2007.

2 - Brunicard FC Schwartz's principles of surgery. McGrawn USA, 8 th. ed. 2007.

3 - Mimi Leong MD, Linda G, Philips MD. Cicatrização. In: Sabiston - tratado de cirurgia - Courtney M. Townsend Jr MD et al. 17a. ed. Elsevier, p. 183-207, 2005.
4 - Araujo ID. Fisiologia da cicatrização. In: Petroian A. Lições de Cirurgia, $1^{\text {a }}$ ed., ed interlivros, p. 101-14, 1997.

Recebido para publicação em 20/08/2008

Aprovado para publicação em 30/09/2008 